\title{
Volatile particles formation during PartEmis: a modelling study
}

\author{
X. Vancassel ${ }^{1, *}$, A. Sorokin ${ }^{2}$, P. Mirabel ${ }^{1}$, A. Petzold $^{3}$, and C. Wilson ${ }^{4}$ \\ ${ }^{1}$ Centre de Géochimie de la Surface, Université Louis Pasteur, Strasbourg, France \\ ${ }^{2}$ Central Institute for Aviation Motors, Moskow, Russia \\ ${ }^{3}$ Deutsches Zentrum für Luft- und Raumfahrt, Oberpfaffenhofen, Germany \\ ${ }^{4}$ QinetiQ, Farnborough, UK \\ *now at: Atmospheric, Oceanic and Planetary Physics, University of Oxford, UK
}

Received: 24 September 2003 - Published in Atmos. Chem. Phys. Discuss.: 18 November 2003

Revised: 1 March 2004 - Accepted: 3 March 2004 - Published: 17 March 2004

\begin{abstract}
A modelling study of the formation of volatile particles in a combustor exhaust has been carried out in the frame of the PartEmis European project. A kinetic model has been used in order to investigate nucleation efficiency of the $\mathrm{H}_{2} \mathrm{O}-\mathrm{H}_{2} \mathrm{SO}_{4}$ binary mixture in the sampling system. A value for the fraction $\varepsilon$ of the fuel sulphur S(IV) converted into $\mathrm{S}(\mathrm{VI})$ has been indirectly deduced from comparisons between model results and measurements. In the present study, $\varepsilon$ ranges between roughly $2.5 \%$ and $6 \%$, depending on the combustor settings and on the value assumed for the parameter describing sulphuric acid wall losses. Soot particles hygroscopicity has also been investigated as their activation is a key parameter for contrail formation. Growth factors of monodisperse particles exposed to high relative humidity (95\%) have been calculated and compared with experimental results. The modelling study confirms that the growth factor increases as the soot particle size decreases.
\end{abstract}

\section{Introduction}

The presence of volatile particles formed in young jet aircraft plumes has been first pointed out in the late 70's (Hofmann and Rosen, 1978). Assumed to be mainly composed of water and sulphuric acid, their induced perturbation on the background aerosol remains difficult to predict with regard to natural sources variability. It is however becoming increasingly apparent that the formation of new particles within the aircraft wake, at cruise altitudes, could have a significant influence on atmospheric radiation processes, chemical composition, and cloud coverage (IPCC, 1999).

The understanding of the potential impacts of aircraft generated aerosol still requires a better knowledge of the mechanisms of particle precursors formation and of ultrafine

Correspondence to: P. Mirabel

(mirabel@illite.u-strasbg.fr) volatile particles generation. Numerous papers, involving insitu measurements (Fahey et al., 1995; Schröder et al., 1998; Brock et al., 2000) and also modelling studies have emphasized the role of sulphur, chemi-ion and organic compounds on aircrafts plume microphysical processes (Yu and Turco, 1997; Kärcher et al., 1998; Yu et al., 1999). However, the effect of engine operating conditions on the formation of these particles is not yet well understood. There is evidence that the number of volatile particles increases with increasing levels of sulphur in the fuel, but the conversion rate $\varepsilon$ at which the original sulphur (IV) is transformed to $\mathrm{S}(\mathrm{VI})$ i.e. $\mathrm{SO}_{3}$ and $\mathrm{H}_{2} \mathrm{SO}_{4}$ remains highly discussed as a wide range of values has already been suggested (Schumann et al., 2002).

For example, on ground measurements by Frenzel and Arnold (1994) yielded $\varepsilon>0.4 \%$ while in flight measurements yielded values of $\varepsilon$ in the range $12-45 \%$ behind a Concorde (Fahey et al., 1995) or 6-31\% behind a B757 (Miake-Lye et al., 1998). More recently, $\varepsilon$ in the range $0.34-4.5 \%$ has been derived for the ATTAS aircraft, a value which depends on the Fuel Sulphur Content FSC (Kärcher et al., 1998; Curtius et al., 1998, 2002; Schumann et al., 2002). A comprehensive list of $\varepsilon$ values deduced from measurements can be found in Schumann et al. (2002). Previous modelling studies also lead to a wide range of $\varepsilon$ values, from about 1-2\% (Brown et al., 1996) to 20-30\% (Yu and Turco, 1997) or even 25-60\% (Kärcher and Fahey, 1997). However, the real situation may not be as confused as it seems and some recent efforts have considerably reduced these apparent discrepancies to $\varepsilon$ values in the range $0.5-5 \%$ (Kärcher et al., 2000) or $0.5-10 \%$ (Schumann et al., 2002).

A precise knowledge about $\varepsilon$ values is needed if one wants to evaluate correctly the aerosol production in the plume, since volatile particles nucleation and then aerosol properties are highly sensitive to sulphuric acid concentration (e.g. Schumann et al., 1996, 2002). Furthermore, these aerosol particles have a large effect on soot activation and contrail formation, although variations in the FSC have only a small 
impact on contrail threshold conditions (Busen and Schumann, 1995). To improve the emission performance of engines, an extensive set of gaseous species and aerosol measurements has been conducted on a jet engine combustor test rig, in the frame of the EU project PartEmis (Measurement and Prediction of Emissions of Aerosols and Gaseous Precursors from Gas Turbine Engines). One of the goals of PartEmis was to gain more information about the rate of sulphur conversion $\varepsilon$. For this, gaseous $\mathrm{S}(\mathrm{VI})\left(\mathrm{SO}_{3}+\mathrm{H}_{2} \mathrm{SO}_{4}\right)$ has been measured by chemical ionization mass spectrometry (Katragkou et al., 2004). In addition, the size distribution in the combustion aerosol size range (diameter $D>10 \mathrm{~nm}$ ) was measured with a Scanning Mobility Particle Sizer (SMPS). Liquid aerosol particles measurements were achieved by operating a multi-channel Condensation Particle Size Analyzer (CPSA; Stein et al., 2001). The CPSA provides number concentrations in the size bins $D=4-7 \mathrm{~nm}$, $7-9 \mathrm{~nm}, 9-20 \mathrm{~nm}$, and $>20 \mathrm{~nm}$. One of the main results is that only the concentrations of particles in the size range 4$7 \mathrm{~nm}$, have shown a dependency on the FSC used during the test campaign (Petzold et al., 2003). Furthermore, the hygroscopic properties of particles with dry diameters $>30 \mathrm{~nm}$ were measured with a Hygroscopicity Tandem Differential Mobility Analyzer (H-TDMA), described by Weingartner et al. (2002).

To support these experiments, several modelling studies have been undertaken and in this article, we present modelling studies of the formation of volatile particles and of the hygroscopic properties of soot particles. Calculations have been performed with a comprehensive microphysical model.

\section{Experimental setup and sampling system}

A brief description of the combustor and test-rig used during PartEmis, is given below, and further details can be found in Wilson et al. (2004). A turbo-annular, transpiration cooled combustor was used for tests on QinetiQ's High Pressure Combustion Rig at Farnborough, UK. Air was delivered from a compressor and heater unit. A back-pressurizing valve located downstream of the combustor maintained the correct pressure in the system. After extraction of sample exhaust at the combustor exit, the remainder of the high-temperature exhaust gases was cooled using water injection via a set of spray-bars. Water-cooled jackets provided additional cooling of pipework.

The exhaust was sampled close to the combustor exit by a probe (4 $\mathrm{mm}$ inner diameter), laterally moved to eleven transverse positions. This allowed the lateral distribution of gaseous and particles to be measured. Note that the extreme positions close to the walls were not used as their air fuel ratios were too far from the average value. After exiting the probe, the sample temperature was rapidly quenched to minimise post sampling reactions, by a water cooling system, bringing its temperature to about $420 \mathrm{~K}$ avoiding any con- densation of water and unburnt hydrocarbons in particular. The exhaust was then split and delivered to a diluted and to an undiluted sampling line which supplied each participant with the desired fraction of the sample. The diluted line, which concerns this study, was not insulated (contrarily to the undiluted line) and the sample naturally attained room temperature $\left(\sim 20^{\circ} \mathrm{C}\right)$ after dilution by a factor of about 60 65. Dilution was achieved by means of a capillary tube with particulate free air at ambient conditions $(293 \mathrm{~K}, 1052 \mathrm{hPa})$. The last part of the sampling line had an inner diameter of $21.12 \mathrm{~mm}$ and the total transit time was approximately $0.9 \mathrm{~s}$ from the tip of the probe to the measurement devices. Note that the Max-Planck Institute (MPI) which studied sulphur conversion mechanisms had its own and shorter sampling line.

Water emission indices have been measured for each position of the probe as the exhaust was not homogeneously mixed. In addition to the water formed during the combustion, the dilution air relative humidity RH (equal to $35 \%$ ) has been taken into account. However, relative humidity was also measured at the end of the sampling line and, at this point the relative humidity was about 5\% (at such low relative humidity the accuracy of the device used is not very good). Thus, we have run our model using mainly a water vapour profile calculated following Eq. (2) with 2 boundary limits: RH (diluter) $=35 \%$ and $\mathrm{RH}$ (end of the tube) $=5 \%$. Two settings were used, in order to reproduce old and modern cruise conditions (see Table 1 for combustor settings details) and three different fuel sulphur contents FSC $=50,410$ and $1270 \mathrm{ppm}$ have been tested. As the extraction probe was very close to the exit smile, the temperature of the exhaust gases in the first part of the sampling line remained high (above $430 \mathrm{~K}$ ) until the dilution point was reached. Therefore, no condensation was expected in this part of the sampling line. On the contrary, the dilution of the sample with air at ambient temperature cooled it down very rapidly (more than $100^{\circ} \mathrm{C}$ in less than $10 \mathrm{~ms}$ ), leading to a local supersaturation of the condensing vapors. Therefore, particle formation was expected to take place only in the sampling line, just after the mixing of the sample with the cold diluting air.

Indeed, volatile particles were detected at the end of the sampling line, in the 4-7 nm size range but only for the high fuel sulphur case (FSC $=1270 \mathrm{ppm})$. Model calculations described below confirm that only for this high FSC volatile particles are expected to be analysed with this experimental set up.

\section{Model description}

Classical homogeneous heteromolecular nucleation theory, generally invoked to explain the formation of volatile particles seems unable to properly describe their formation in aircraft plumes because of the use of a steady state approach leading to time lag effects in a fast changing system ( $\mathrm{Yu}$ and 
Table 1. Main settings of the combustor during PartEmis.

\begin{tabular}{ccc}
\hline Combustor parameters & Old cruise conditions & Modern cruise conditions \\
\hline $\mathrm{T}_{\text {ci }}$ combustor inlet $(\mathrm{K})$ & 566 & 766 \\
$\mathrm{~T}_{\text {co }}$ combustor outlet $(\mathrm{K})$ & 1125 & 1448 \\
$\mathrm{P}_{\text {co outlet pressure }\left(10^{5} \mathrm{~Pa}\right)}$ & 7.05 & 8.2 \\
Air mass flow $\left(\mathrm{kg} \mathrm{s}^{-1}\right)$ & 2.12 & 2.12 \\
Fuel-flow $\left(\mathrm{kg} \mathrm{s}^{-1}\right)$ & 0.032 & 0.042 \\
Air fuel ratio & 66 & 50.3 \\
\hline
\end{tabular}

Turco, 1997; Taleb et al.,1997). Indeed, in a plume, temperature cools down very rapidly due to the entrainment of very cold ambient air in the wake. As a consequence, we have used a kinetic microphysical approach, similar to the one used by Yu and Turco (1997) (see also Yu and Turco, 2001). The model, based on coagulation processes in the sulphuric acid-water binary mixture (Sorokin et al., 2001) takes into account both charged (ions or charged clusters) and neutral species (molecules or clusters), the presence of charges having a stabilizing effect on clusters and enhances growth and coagulation. Large concentrations of chemi-ions have indeed been noted in aircraft engines or exhaust plumes (Arnold et al., 1998; Sorokin and Mirabel, 2001).

Contrarily to the classical nucleation theory which assumes that particles result from collisions between clusters and single molecules (or hydrates), the kinetic approach includes in addition cluster-cluster collisions. In the case of particle formation from the sulphuric acid- water system, previous studies have revealed several interesting features which have been applied here: (i) given the very strong binding energy between sulphuric acid and water molecules, the formation of hydrates is expected in the vapor phase (Heist and Reiss, 1974; Jaecker-Voirol et al., 1987; Noppel et al., 2002). In fact, calculations show that most of the acid molecules are bound into stable hydrates made out of $\mathrm{N}_{\mathrm{a}}$ acid molecules and $h$ water molecules; (ii) because of the very high dissymmetry between the vapor pressures of water and sulfuric acid (about 8-10 orders of magnitude) it is assumed that, between the incorporation of sulfuric acid molecules in a cluster, a cluster is in quasi-equilibrium with respect to exchange of water molecules (Mirabel and Katz, 1974). This assumption which has been widely used in the literature concerning the atmosphere implies that for a given relative humidity the number of water molecules and therefore the size of a cluster (or in a particle) is determined by its number of acid molecules $\mathrm{N}_{\mathrm{a}}$. The amount of water condensed on volatile particles has been assumed to adjust instantaneously to its equilibrium value as the exhaust remained subsaturated $(\mathrm{RH}<100 \%)$.

The initial distribution of sulphuric acid hydrates has been calculated following Wilemski and Wyslouzil self consistent assumptions (Wilemski and Wyslouzil, 1995). The subse- quent growth due to coagulation and condensation (condensation has been treated as a special case of coagulation) has led to the formation of stable particles, classified into sizebins according to their acid content. The number of size bins used, combined with a small Volume Ratio has been chosen in order to avoid numerical diffusion (Sorokin et al., 2001), a phenomenon well known to occur when using a stationary grid (Jacobson et al., 1994). Particle collision efficiency has been assumed to be size dependent for neutral-neutral particles collisions and fixed to unity for any other collision ( $\mathrm{Yu}$, 1998).

In addition to volatile particles, the presence of soot particles in the exhaust has been considered. A log normal distribution has been proposed from measurements results, depending on the probe position. The particle emission index (PEI) was typical for common aircraft engines (PEI $=10^{14}$ to $10^{15}$ soot particles/kg fuel) and the mean size was around $37-$ $40 \mathrm{~nm}$, for old and modern cruise, respectively (details about the combustor operating conditions can be found in Table 1). The interactions between soot particles and gaseous species (water and sulphuric acid) as well as their interaction with volatile particles have been included in the model.

Another key parameter for volatile particles modelling is the Chemi-Ion (CI) emission index at the combustor exit. An upper (lower) value of the CI emission index of 5.3.1017 $\left(5.3 .10^{16}\right) \mathrm{CI} / \mathrm{kg}$ fuel has been proposed by MPI. We mainly used the upper value as a reference one although we have performed a sensitivity analysis of the CI effects on volatile particles growth.

The system of intrusive sampling used to carry out measurements during the Partemis campaign has required the integration of peculiar processes to describe the evolution of species in the exhaust plume. The possible interaction between aerosols (volatile particles and soot) or gaseous species with the flow pipe walls has been taken into consideration. Concerning soot adsorption on the surfaces of the sampling line, we have followed the work by Hurley (1996) who provided the ratio $N_{\text {soot }} / N_{\text {soot }}^{0}$ of leaving to entering soot number densities in a tube. It is interesting to note that losses were found independent of the particle number density and size (as long as they remain in the size range 40-100 nm). For stainless steel, losses have been calculated according to 


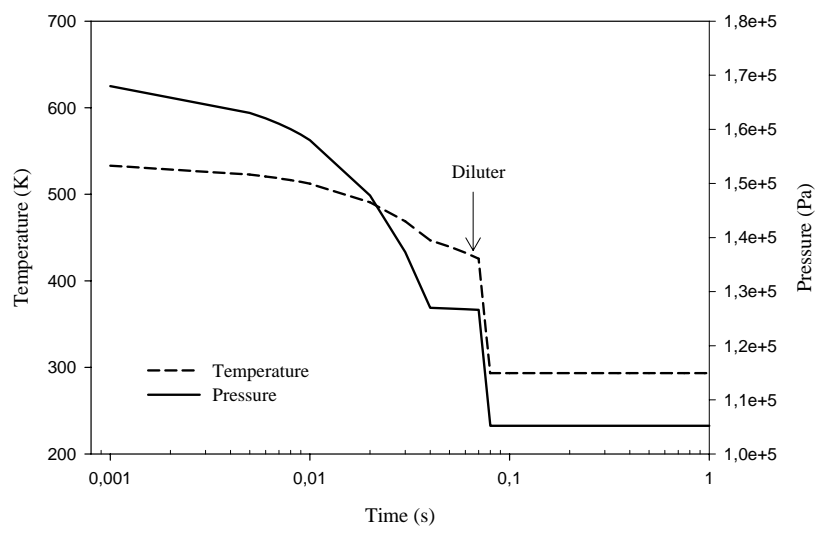

Fig. 1. Temperature (left y axis) and pressure (right y axis) evolution in the sampling tube for modern cruise conditions, after extraction of the exhaust gas by the probe, after the combustor exit.

the semi-empirical equation:

$\frac{N_{\text {soot }}}{N_{\text {soot }}^{0}}=\exp \left(-\left(1.05 \times 10^{-4} V+2.27 \times 10^{-4}\right) \frac{L}{d V}\right)$

where $N_{\text {soot }}^{0}$ and $N_{\text {soot }}$ are respectively the soot particles number density at the entrance and at the end of the tube, $V$ is the sample mean velocity, $L$ the pipe length and $d$ its diameter. Equation (1) has been used for the series of pipes of different sections with varying flow rate, which constitute the PartEmis sampling line geometry.

Concerning volatile particles, wall losses have been neglected from the tip of the probe to the diluter, as the sample was heated at $423 \mathrm{~K}$ to prevent condensation. But after dilution, the estimated material loss due to wall effects, enhanced by the turbulent behaviour of the flow (Reynolds number larger than 30000), was estimated following the work of Brockmann et al. (1982). The volatile particles number density evolution in the tube was then calculated using the first order equation:

$\frac{\partial N(r, t)}{\partial t}=-\frac{4 k_{T}(r, T)}{d} N(r, t)$,

where $N(r, t)$ is the number density of volatile particles of radius $r$ at time $t$ after the diluter, $T$ the temperature of the sample and $k_{T}$ is the mass transfer coefficient determined according to Friedlander (1977) (see for example Brockmann et al., 1982):

$k_{T}=0.042 V f^{1 / 2} S c^{-2 / 3}$,

where $V$ is the sample mean velocity, $f$ the friction factor and $S c$ the Schmidt number. The friction factor is given by Bird et al. (1960):

$f=0.0791 \times R e^{-1 / 4}$, where $R e$ is the Reynolds number, characterizing the flow in the pipe and defined as

$R e=\frac{V d}{v(T)}$,

where $v(T)$ is the viscosity of air ( $V$ and $d$ have been previously defined). Finally the Schmidt number used in Eq. (3) which estimates the ratio between the viscosity of air $v(T)$ and the particle diffusivity $D(r, T)$ is expressed by

$S c=\frac{v(T)}{D(r, T)}$,

where $r$ and $T$ have been defined for Eq. (2). Equation (4) finally leads to $f \approx 0.006$, a value confirmed by QinetiQ engineers (Hurley, personal communication).

\section{Results and discussion}

\subsection{Volatile particles}

The knowledge of the temperature profile in the sampling line is needed to calculate the rate of formation of new particles since the temperature controls the evolution of the saturation ratio of both condensing species. The temperature at the tip of the probe has been deduced from QinetiQ's and MPI's measurements as the pressure drop and the temperature at the sampling location for the chemical ionization mass spectrometry ( $3 \mathrm{~m}$ downstream the probe head) were known. The temperature and pressure at the tip of the probe were approximately of $530 \mathrm{~K}(600 \mathrm{~K})$ and $168000 \mathrm{~Pa}(172000 \mathrm{~Pa})$ for old (modern) cruise conditions. Figure 1 shows the typical evolution of the temperature and pressure in the sampling line for modern cruise conditions (Hurley, personal communication). This plot shows the decrease of temperature and pressure when dilution occurs. This point is very important as the decrease of the sample temperature triggered off the formation of particles due to the saturation increase of the sulphuric acid-water mixture. The kind of cruise considered (old or modern) has an effect on the temperature and pressure as long as the sample is situated before the diluter. However, in these regions, temperature remains high enough $(>400 \mathrm{~K})$ to prevent any formation of particles. Therefore the final number concentrations of volatile particles calculated by varying the profiles before the diluter (but keeping the initial and final temperature constant) are similar.

Figure 2, which shows the evolution of the total number concentration of volatile particles confirms the importance of the diluting point as the particles concentration time evolution exhibits a steep increase just after this point $(\sim 0.08 \mathrm{~s})$. As temperature falls down, saturation of condensable species increases and particles form.

One of the main uncertainties to calculate losses is the value to be affected to the sticking coefficient, i.e. to determine a collision efficiency (CE) between particles or clusters 


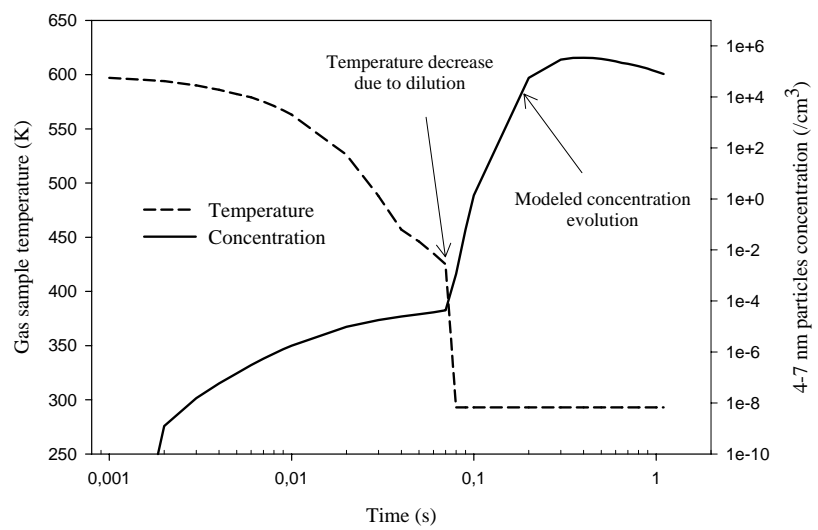

Fig. 2. Calculated evolution of volatile particles concentration (right $\mathrm{y}$ axis) and temperature (left y axis) in the sampling line for a given probe position.

colliding on the tube walls. Several values of CE have been used, from $50 \%$ to $100 \%$ (maximum possible value) as this parameter remains poorly known. Actually, even for two colliding particles or molecules, theoretical studies as well as experiments have led to quite different values of accommodation coefficient (Van Dingenen and Raes, 1991; Clement et al., 1996).

Figure 3 which gives the results of the simulations for high FSC, shows the sulphur conversion factor required for the model to provide a good agreement with measured volatile particles concentration in the size range $4-7 \mathrm{~nm}$. The different curves correspond to different values for the assumed CE and sulphur conversion factors $\varepsilon$. For the maximum possible value $\mathrm{CE}=100 \%$, the sulphur conversion factor reaches a mean value of about $5.2 \%$ for old and $5.7 \%$ for modern cruise conditions. However, if the $\mathrm{CE}$ is reduced to $50 \%$ (still a rather high value), $\varepsilon$ mean values translate to $2.5 \%$ and $2.8 \%$, respectively. These last values provide very reasonable agreement both with the measured concentration of volatile particles and $\varepsilon$ values deduced by the MPI group, although most of these results have been determined in the wake, and not at the combustor exit (e.g. Curtius et al., 2002). These results are particularly important as they provide a range of the sulphur conversion $\varepsilon$ whose value was still uncertain (Schumann et al., 2002). Besides, the range proposed is rather narrow compared to previous studies (e.g. Kärcher and $\mathrm{Fa}-$ hey, 1997) as it extends from roughly $2.5 \%$ to $6 \%$. Measurements of sulphur species during PartEmis have also indicated a slight increase of $\varepsilon$, from old to modern cruise (Katragkou et al., 2004). This trend is visible on Fig. 3 but only for the probe positions 5 to 8 . Note that results for the first and last positions of the probe, close to the combustor wall have not been presented here, as the air fuel ratio (AFR) in these cases was much higher than the average value (approximately twice the average AFR).

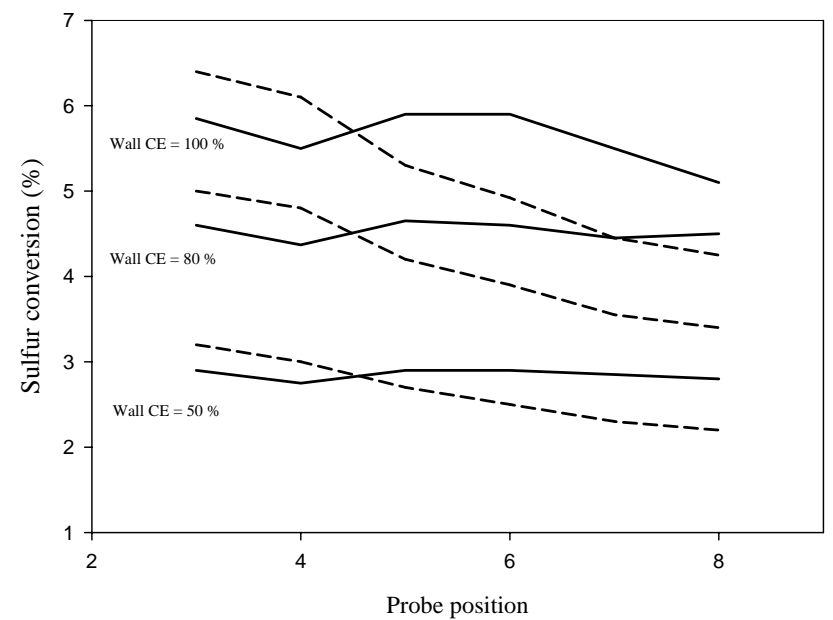

Fig. 3. Sulphur conversion factor $\varepsilon$ required to obtain the same volatile particle concentrations as in DLR measurements, as a function of the probe position. Case of high FSC (1270 ppm). Dashed lines: old cruise. Solid lines: modern cruise. The agreement between observations and calculations is good for $\varepsilon$ comprised between $2.5 \%$ and $6 \%$ approximately, whatever the collision efficiency CE used.

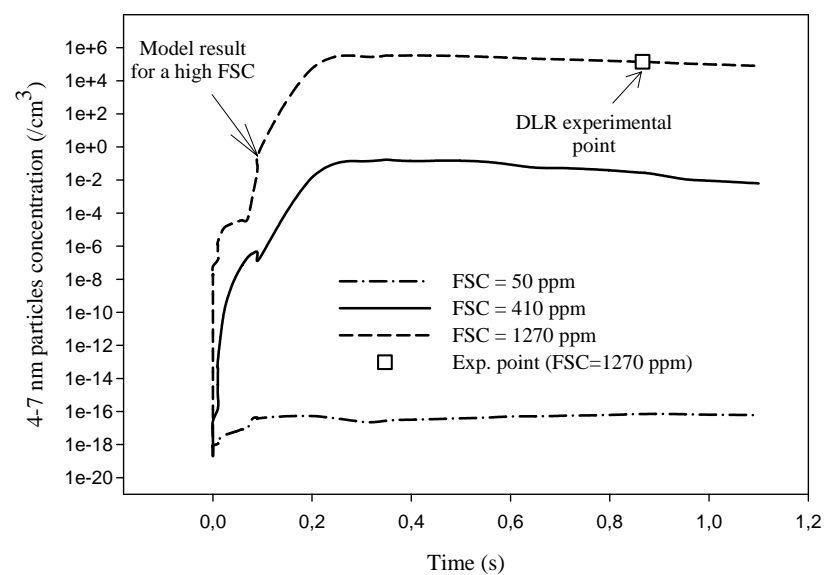

Fig. 4. Time evolution of $4-7 \mathrm{~nm}$ volatile particles concentration in the sampling line, as a function of the fuel sulfur content FSC. Modern cruise operating conditions. Probe position 5. $\varepsilon=2.7 \%$, $\mathrm{CE}=50 \%$. The experimental point is plotted without uncertainties. This plot confirms experimental finding that volatile particles were observed only when burning the high FSC fuel. The couple $\mathrm{CE}=50 \%-\varepsilon=2.7 \%$, matches well the experimental point.

The calculated time evolution of volatile particles concentration in the sampling line has been plotted on Fig. 4, for different fuel sulphur contents, as well as the experimental point obtained during the PartEmis test campaign for the high sulphur case $(\mathrm{FSC}=1270 \mathrm{ppm})$. The most favourable case for particles formation has been considered in the model, as we used $\mathrm{CE}=50 \%$. We found a very good agreement between 


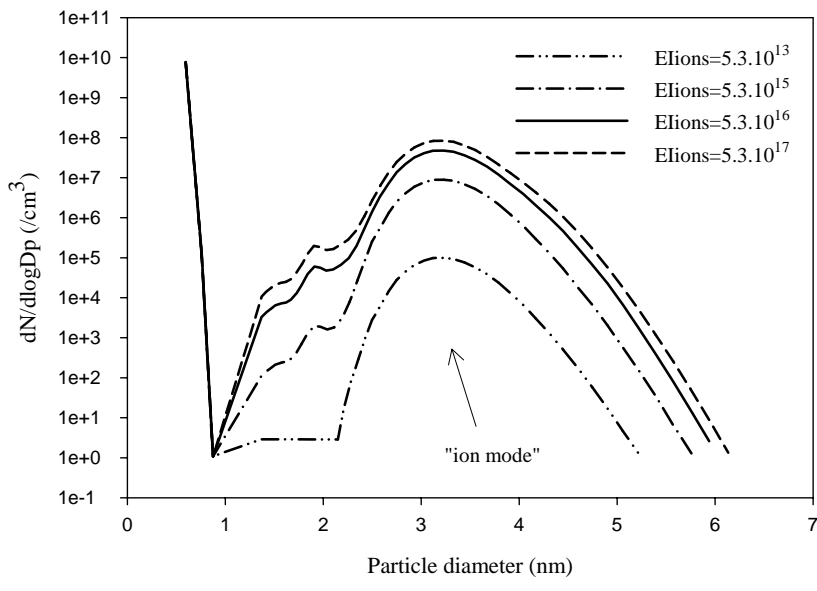

Fig. 5. Volatile particles size distribution as a function of the initial Chemi Ion emission index EIions (in number of chemi ions per kilogram of fuel burnt). Note that the size distribution changes only a little when using Elions=5.3.10 ${ }^{17}$ or $5.3 .10^{16}$ chemi ions per $\mathrm{kg}$ of fuel, the upper and lower limits of the range given by MPI.

model results and the experimental result using $\varepsilon=2.7 \%$. A very important point is that for this sulphur conversion factor, no particles are expected to be seen at the end of the sampling line from our model results, when using the low and the medium FSC (50 ppm and $410 \mathrm{ppm}$, respectively). This is in agreement with observations, as particles were detected only for the high FSC. We have also increased the sulphur conversion factor $\varepsilon$ up to values larger than $5 \%$ and even in that case no volatile particles were formed in the low or medium FSC case. These findings seem to be in contradiction with in-flight measurements, in which volatile particles were observed even for FSC lower than 100 ppm (see Schumann et al., 2002). The main reason for these discrepancies lay on the wall losses for gases and particles, as calculated by Eqs. (12).

The sulphur conversion $\varepsilon$ and the collision efficiency on walls are not the only parameters which have an influence on particles growth. Chemi-ion concentrations, which were measured during PartEmis, may play also a major role. As already noted, we have used an emission index of $5.3 .10^{17} / \mathrm{kg}$ at the combustor exit.

Figure 5 depicts the size distribution of particles calculated for $\varepsilon=2.7 \%$ and $\mathrm{CE}=50 \%$, as a function of different initial amount of CI present in the exhaust (note that the use of $\varepsilon=5 \%$ and $\mathrm{CE}=100 \%$, would lead to the same result). As it can be seen from these plots, decreasing the $\mathrm{CI}$ emission index we used $\left(5.3 .10^{17} / \mathrm{kg}\right.$ fuel) by a factor 10 (leading to the lowest value suggested by MPI) has a very limited influence on the final particle concentrations. This mainly indicates that using a different $\mathrm{CI}$ emission index in the range proposed by MPI should not affect a lot our estimate of $\varepsilon$ (for the probe position 5 - old cruise - and $\mathrm{CE}=50 \%$, to fit measurements, $\varepsilon$ should be increased from $2.7 \%$ to $2.9 \%$ to com-

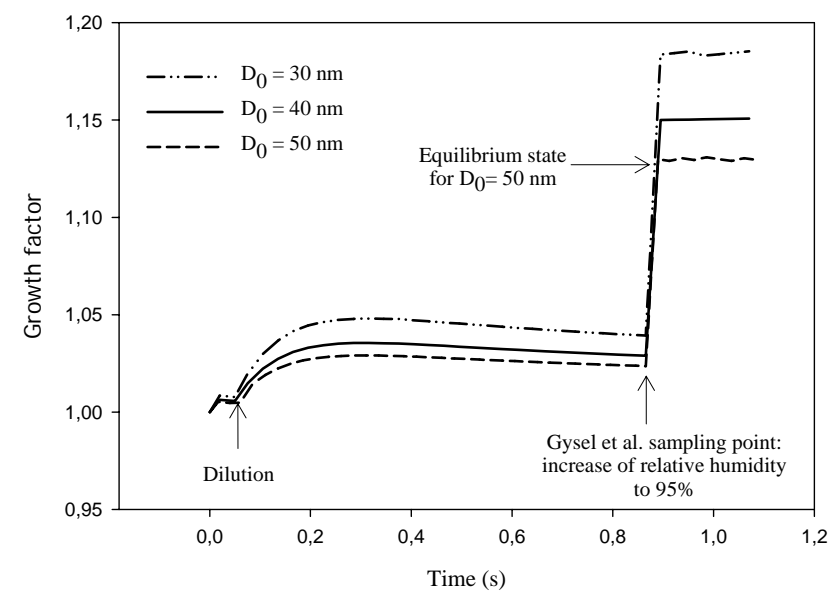

Fig. 6. Soot particles growth factor evolution in the sampling line and after Gysel et al. (2003) sampling. Note that the growth factor presented here is different from the one presented in Table 2 as it refers to an initial dry diameter at the tip of the probe and not just before the sampling point (at $t \sim 0.9 \mathrm{~s}$ ).

pensate the effect of decreasing the initial amount of chemi ion from $5.3 .10^{17} / \mathrm{kg}$ fuel to $5.3 .10^{16} / \mathrm{kg}$ fuel).

As already mentioned by Yu and Turco (1997), the size distribution generally exhibits a bimodal structure: a larger ion mode and a smaller neutral mode. The ion mode is partly composed of neutral particles, formed by ion-ion recombination, and of charged particles, mainly formed by ionattachment. The bimodal structure results from the presence of both charged and neutral clusters and also from the use of a size dependent accommodation coefficient for neutralneutral particles collisions. By limiting the efficiency of collision between neutral particles for small sizes, the role of ions on particles growth is then enhanced. In our case, the first mode (neutral mode) is not well developed as it is essentially composed of particles smaller than $2 \mathrm{~nm}$. Since smaller particles have higher diffusion coefficients, their depletion by wall losses is very efficient. This is why the concentration of small particles is very low, especially when compared to real plumes, even several seconds after emission (e.g. Sorokin et al., 2001). Unfortunately, the curves of Fig. 5 cannot be compared with any measurements since the size distribution in the $4-7 \mathrm{~nm}$ range was not resolved.

\subsection{Hygroscopic properties of soot particles}

Soot particles have been taken into account in our calculations and we have studied the ability of the model to reproduce soot particles growth measurements, as they have been carried out by Gysel et al. (2003). Actually, studies of soot hygroscopicity are of main importance as soot activation is a key process for their subsequent growth and transformation into contrails. To summarize briefly these experiments, a monodisperse fraction of particles has been sampled, at the 
Table 2. Experimental (Gysel et al., 2003) and model results (this work). Comparison of soot particles growth factor and sulphuric acid volume fraction for modern cruise operating conditions at high FSC (1270 ppm). The growth factor is calculated as the ratio between the particles diameters considered just before they enter the condensation chamber and after they reach equilibrium in it.

\begin{tabular}{ccccc}
\hline $\begin{array}{c}\text { Dry diameter } \\
(\mathrm{nm})\end{array}$ & $\begin{array}{c}\text { Calculated growth } \\
\text { factor } \\
\text { (this work) }\end{array}$ & $\begin{array}{c}\text { Measured growth } \\
\text { factor (Gysel et } \\
\text { al., 2003) }\end{array}$ & $\begin{array}{c}\text { Calculated acid } \\
\text { volume fraction } \\
(\%)(\text { this work) }\end{array}$ & $\begin{array}{c}\text { Estimated acid } \\
\text { volume fraction }\end{array}$ \\
30 & 1.14 & 1.23 & 14.0 & (Gysel et al., 2003) \\
50 & 1.11 & 1.16 & 9.6 & 21.0 \\
100 & 1.07 & 1.07 & 8.4 & 9.5 \\
\hline
\end{tabular}

end of the sampling line, and then exposed to a rather high relative humidity (up to $95 \%$ ).

Although soot activation has recently been observed to occur even with sulphur free kerosene (Popovicheva, personal communication), Gysel et al. (2003) have shown a clear dependence between the fuel sulphur content and the growth factor defined as the ratio between the wet and the dry (initial) diameter of soot particles, calculated once they have been exposed to high humidity conditions. As volatile and soot particles undergo scavenging processes, soot particles have gained a sulphuric acid-water coating as they have been transported in the sampling line. We have then checked if the model results could match experimental results, concerning both the measured growth factor and the estimated sulphuric acid weight fraction of the layer. On Fig. 6, the time evolution of soot particles growth factor has been plotted, as a function of the time spent in the sampling line, until they are exposed to high relative humidity $(t>0.9 \mathrm{~s})$.

The growth factor is characterized by a slight increase close to the diluter when the sample is mixed with the diluting air whose humidity is higher. Then the liquid coating evaporates slightly as both water and sulphuric acid molecules are lost on the walls or are depleted due to nucleation and condensation processes. At the end of the sampling line, when the sample enters the H-TDMA the sudden increase of relative humidity, up to $95 \%$ brings about a sudden growth of soot particles. As noted by Gysel et al. (2003), the smaller the particles, the larger the growth factors are and no significant difference was detected between old and modern conditions (especially if error bars are included). These observations were confirmed by our modelling study since the calculated growth factors (independent of the flight conditions: old or modern cruise) are 1.14, 1.11 and 1.07 respectively for particles having initial diameters of 30, 40 and $50 \mathrm{~nm}$ before extraction. These values are close to those calculated for other probe positions and have been obtained using a wall CE $50 \%$ and a sulphur conversion corresponding to the one required to fit volatile particles concentration to the measurements carried out by the Deutsches Zentrum für Luft- und Raumfahrt (DLR) $(\varepsilon=2.5-2.8 \%)$. Table 2 gives a comparison between calculated and measured growth factors and acid volume fractions of the surface layer, for the high
FSC case ( $\mathrm{FSC}=1270 \mathrm{ppm})$. One notes a good agreement for the general trends, i.e. increase of both growth factors and acid volume fractions with decreasing size. However, the values may be quite different, especially for the acid volume fraction. Both Table 2 and Fig. 6 confirm that the $\mathrm{H}_{2} \mathrm{SO}_{4}$ volume fraction of soot particles is a key point in their hygroscopic behaviour as the growth factor increases with the amount of sulphuric acid which covers soot particles.

\section{Conclusions}

A modelling study of volatile particle formation has been presented in the frame of the PartEmis project, in order to study the role of sulphuric acid on particles formation and growth. A sulphur conversion factor $\varepsilon$ has been indirectly deduced from the comparison between experimental results and model calculations. Taking into account the absence of accurate monitoring of water vapour along the line, and the lack of line transmission information, average values in the ranges $2.5 \%$ and $5.7 \%$ have been calculated, depending on the collision efficiency of particles and clusters on the walls. The last value of $\varepsilon$ cited, (5.7\%) represents an upper limit since it has been deduced for the maximum collision efficiency between particles and sampling line walls. This value is very important as particle formation in an aircraft plume strongly depends on the amount of sulphuric acid emitted. This work also indicates that the value of $\varepsilon$ is probably smaller than many other suggested values (Schumann et al., 2002) which is confirmed by recent measurements (Curtius et al., 2002; Katragkou et al., 2004). Furthermore this modelling study supports experimental observations, concerning volatile particles formation as well as soot hygroscopic behaviour. Calculations confirmed the absence of volatile particles observed while using low and medium sulphur case. Besides the soot growth factor study has pointed out similar trends between measured and calculated values. In particular, the growth factor increases as the soot particle size decreases (Gysel et al., 2003). The main reason invoked by these authors about that trend (influence of a different acid volume fraction) has been supported by calculations as our results have revealed that the acid volume fraction was lower for larger particles. 
Finally, the role of sulphuric acid in soot growth has been confirmed by results from our kinetic model.

The role of sulphuric acid remains very important, although the binary system may not be completely able to predict accurately particles concentration, especially in a complex system such as a sampling line. Our modelling study did not include the possible contribution of organics on the growth process. However, previous studies have shown that this role appears to be important only for low FSC (of the order of $100 \mathrm{ppm}$ or less). Another source of uncertainty is the possible presence of ammonia (which was not monitored) in the diluting air, as ammonia is known to lead to ternary nucleation with the sulphuric acid-water mixture. If ammonia was indeed present, nucleation would have been enhanced and the value of $\varepsilon$ needed in the model would have been reduced. Again, this confirms that the $\varepsilon$ values given in this work should be considered as upper limits.

Acknowledgements. Support of this work by the European Community through contract G4RD-CT-2000-00207 (PartEmis) and by the INTAS project OPEN 2000-460, as well as fruitful discussions with the PartEmis participants are gratefully acknowledged.

Edited by: J. Abbatt

\section{References}

Arnold, F., Wohlfrom, K. H., Klemm, M. W., Schneider, J., Gollinger, K., Schumann, U., and Busen, R.: First gaseous ion composition measurements in the exhaust plume of a jet aircraft in flight: Implication for gaseous sulfuric acid, aerosols, and chemiions, Geophys. Res. Let., 25, 2137-2140, 1998.

Arnold, F., Kiendler, A., Wiedemer, V., Aberle, S., and Stilp, T.: Chemiion concentration measurements in jet engine exhaust at the ground: Implications for ion chemistry and aerosol formation in the wake of a jet aircraft, Geophys. Res. Let., 27, 1723-1726, 2000.

Bird, R. B., Stewart, W. E., and Lightfoot, E. N.: Transport Phenomena, Wiley International Edition, 1960.

Brock, C. A., Schröder, F., Kärcher, B., Petzold, A., Busen, R., and Fiebig, M.: Ultrafine particle size distribution measured in aircraft exhaust plumes, J. Geophys. Res., 105, 26 555-26567, 2000.

Brockmann, J. E., McMurry, P. H., and Liu, B. Y. H.: On simultaneous coagulation and diffusional loss of free molecule aerosols in turbulent pipe flow, Aeros. Sci. Tech., 1, 163-178, 1982.

Brown, R. C., Miake-Lye, R. C., Anderson, M. R., Kolb, C. E., and Resch, T. J.: Aerosol dynamics in near-field aircraft plumes, J. Geophys. Res., 101, 22 939-22 954, 1996.

Busen, R. and Schumann, U.: Visible contrail formation from fuels with different sulphur contents, Geophys. Res. Let., 22, 13571360, 1995.

Clement, C. F., Kulmala, M., and Vesala, T.: Theoretical considerations on sticking probabilities, J. Aeros. Sci., 27, 869-882, 1996.

Curtius, J., Siereau, B., Arnold, F., Baumann, R., Busen, R., Schulte, P., and Schumann, U.: First direct sulfuric acid detection in the exhaust plume of a jet aircraft in flight, Geophys. Res. Let., 25, 923-926, 1998.
Curtius, J., Arnold, F., and Schulte, P.: Sulfuric acid measurements in the exhaust plume of a jet aircraft in flight: Implications for the sulfuric acid formation efficiency, Geophys. Res. Let., 29, doi:10.1029/2001GL013813, 2002.

Fahey, D. W., Keim, E. R., Boering, K. A., Brock, C. A. et al.: Emission measurements of the Concorde supersonic aircraft in the lower stratosphere, Science, 270, 70-74, 1995.

Frenzel, A. and Arnold, F.: Sulphuric acid cluster ion formation by jet engines: Implications for sulphuric acid formation and nucleation, In: Proc. Intern. Scientific Coll. On Impact from Aircraft and Spacecraft upon the Atmosphere, Köln 1994, DLR-Mitt. 9406, 106-112, 1994.

Friedlander, S. K.: Smoke, Dust and Haze, Eds Wiley, New York, 1977.

Gysel, M., Nyeki, S., Weingartner, E., Baltensperger, U., Giebl, H., Hintzenberger, R., Petzold, A., and Wilson, C. W.: Properties of jet engine combustor particles during the PartEmis experiment. Hygroscopicity at subsaturated conditions, Geophys. Res. Let., 30, 1566, doi: 10.1029/2003GL016896, 2003.

Heist, R. H. and Reiss, H.: Hydrates in supersaturated binary sulfuric acid-water vapor, J. Chem. Phys., 61, 573-581, 1974.

Hofmann, D. J. and Rosen, J. M.: Balloon observations of a particle layer injected by stratospheric aircraft at $23 \mathrm{~km}$, Geophys. Res. Let., 5, 511-514, 1978.

Hurley, C. D.: Measurements of particulates from an engine combustor, AEROTRACE proceedings, Impact of Aircraft Emissions upon the Atmosphere, Paris, 1, 113, 1996.

Intergovernmental Panel on Climate Change (IPCC): Aviation and the Global Atmosphere, edited by Penner, J. E., Lister, D. H., Griggs, D. J., Dokken, D. J., and McFarland, M., Cambridge Univ. Press, New York, 1999.

Jacobson, M. Z., Turco, R. P., Jensen, E. J., and Toon, O. B.: Modelling coagulation among particles of different composition and size, Atmos. Environ., 28, 1327-1337, 1994.

Jaecker-Voirol, A., Mirabel, P., and Reiss, H.: Hydrates in supersaturated binary sulfuric acid water vapor: a reexamination, J. Chem. Phys., 87, 4849-4852, 1987.

Kärcher, B., and Fahey, D. W.: The role of sulfur emission in volatile particle formation in jet aircraft exhaust plume, Geophys. Res. Let., 24, 389-392, 1997.

Kärcher, B., Yu, F., Schröder, F. P., and Turco, R. P.: Ultrafine aerosol particles in aircraft plumes: Analysis of growth mechanisms, Geophys. Res. Let., 25, 2793-2796, 1998.

Kärcher, B., Turco R. P., Yu, F., Danilin, M. Y., Weisenstein, D. K., Miake-Lye, R. C., and Busen, R.: A unified model for ultrafine aircraft particles emissions, J. Geophys. Res., 105, 2937929386, 2000.

Katragkou, E., Wilhelm, S., Arnold, F., and Wilson, C.: First gaseous Sulfur (VI) measurements in the simulated internal flow of an aircraft gas turbine engine during project PartEmis, Geophys. Res. Lett., Vol. 31, No. 2, L02117, 10.1029/2003GL018231, 2004.

Miake-Lye, R. C., Anderson, B. E., Cofer, W. R., Wallis, H. A., Nowicki, G. D., Ballenthin, J. O., Hunton, D. E., Knighton, W. B., Miller, T. M., Seeley, J. V., and Viggiano, A. A.: $\mathrm{SO}_{\mathrm{x}}$ oxidation and volatile aerosol in aircraft exhaust plumes depend on fuel sulfur content, Geophys. Res. Let., 25, 1766-1680, 1998.

Mirabel, P., and Katz, J. L.: Binary homogeneous nucleation as a mechanism for the formation of aerosols, J. Chem. Phys., 60, 
1138-1144, 1974.

Noppel, M., Vehkamaki, H., and Kulmala, M.: An improved model for hydrate formation in sulfuric acid water nucleation, J. Chem. Phys., 116, 218-228, 2002.

Petzold A., Stein , C., Nyeki, S., Gysel, M., Weingartner, E., Baltensperger, U., Giebl, H., Hitzenberger, R., Döpelheuer, A., Vrchoticky, S., Puxbaum, H., Johnson, M., Hurley, C. D., Marsh, R., and Wilson, C. W.: Properties of jet engine combustor particles during the PartEmis experiment, Part I: Microphysics and Chemistry, Geophys. Res. Let., 30, 10.1029/2003GL017283, 2003.

Schröder, F., Kärcher, B., Petzold, A., Baumann, R., Busen, R., Hoell, C., and Schumann, U.: Ultrafine aerosol particles in aircraft plumes: in situ observations, Geophys. Res. Let., 25, 2789 2792, 1998.

Schumann, U., Ström, J., Busen, R., Baumann, K., Gierens, K., Krautstrunk, F., Schröder, F. P., and Stingl, J.: In situ observations of particles in jet aircraft exhausts and contrails for different sulfur containing fuels, J. Geophys. Res., 101, 6853-6869, 1996.

Schumann, U., Arnold, F., Busen, R., Curtius, J., Kärcher, B., Kiendler, A., Petzold, A., Schlager, H., Schröder, F., and Wohlfrom, K.-H.: Influence of fuel sulfur on the composition of aircraft exhaust plumes: The experiments SULFUR 1-7, J. Geophys. Res., 107, 10.1029/2001JD000813, 2002.

Sorokin, A. and Mirabel, P.: Ion recombination in Aircraft Exhaust Plumes, Geophys. Res. Let., 28, 955-958, 2001.

Sorokin, A., Vancassel, X., and Mirabel, P.: On volatile particle formation in aircraft exhaust plumes, Phys. Chem. Earth (C), 26, 557-561, 2001.

Stein, C., Schröder, F., and Petzold, A.: The Condensation Particle Size Analyzer: A new instrument for the measurement of ultrafine aerosol size distributions, J. Aerosol Sci., 32, S381-S382, 2001.
Taleb, D. E., McGraw, R., and Mirabel, P.: Time lag effects on the binary homogeneous nucleation of aerosols in the wake of an aircraft, J. Geophys. Res., 102, 12 885-12 890, 1997.

Van Dingenen, R. and Raes, F.: Determination of the condensation accommodation coefficient of sulphuric acid on water-sulphuric acid aerosol, Aero. Sci. Tech., 15, 93-106, 1991.

Weingartner, E., Gysel, M., and Baltensperger, U.: Hygroscopicity of aerosol particles at low temperatures 1 . New low-temperature H-TDMA instrument: Setup and first applications, Environ. Sci. Technol., 36, 55-62, 2002.

Wilemski, G. and Wyslouzil, B. E.: Binary nucleation kinetics, I. Self consistent size distribution, J. Chem. Phys., 103, 11271136, 1995.

Wilson C. W., Petzold A., Nyeki S., Schumann U., and Zellner R.: Measurement and Prediction of Emissions of Aerosols and Gaseous Precursors from Gas Turbine Engines (PartEmis): An Overview, Aerosp. Sci. Techn., 8, 131-143, 2004.

Yu, F.: A study of the formation and evolution of aerosols and contrails in aircraft wakes: Development, validation and application of an advanced particle microphysics (APM) model, Ph.D. thesis, Univ. of Calif., Los Angeles, 1998.

Yu, F. and Turco, R. P.: The role of ions in the formation and evolution of particles in aircraft plumes, Geophys. Res. Let., 24, 19271930, 1997.

Yu, F., Turco, R. P., Kärcher B., and Schröder, F.: On the mechanisms controlling the formation and properties of volatile particles in aircraft wakes, Geophys. Res. Lett., 25, 3839-3842, 1998.

Yu, F., Turco, R. P., and Kärcher, B.: The possible role of organics in the formation and evolution of ultrafine aircraft particles, J. Geophys. Res., 104, 4079-4087, 1999.

Yu, F. and Turco, R. P.: From molecular clusters to nanoparticles: Role of ambient ionization in tropospheric aerosol formation, $\mathbf{J}$ Geophys. Res., 106, 4797-4814, 2001. 